\title{
IMAGINAÇÃO E PESQUISA: APONTAMENTOS E FUGAS A PARTIR D'A POÉTICA DO ESPAÇO*
}

\author{
Wenceslao Machado de Oliveira Jr.**
}

\begin{abstract}
RESUMO: A escrita deste ensaio pautou-se numa tripla perspectiva: apresentar alguns escritos de Gaston Bachelard acerca da imaginação como faculdade humana criadora, apresentar e discutir certo caminho metodológico seguido nas pesquisas desenvolvidas pelo autor do ensaio e, paralelo a estas duas primeiras, inserir linhas de fuga e de adensamentos das duas primeiras perspectivas. O diálogo entre os escritos de Bachelard e os do autor do ensaio compõe o texto principal. Ao largo dele são indicados pensamentos que conectam e dispersam este diálogo central a outros autores e idéias.
\end{abstract}

Palavras-chave: Imaginação. Pesquisa. Imagem poética. Gaston Bachelard.

\section{IMAGINATION AND RESEARCH: NOTES AND ESCAPES FROM THE POETICS OF SPACE}

ABSTRACT: This essay was written from a triple perspective: presenting some of Gaston Bachelard's writings on imagination as a human creative faculty, bringing forth and discussing the methodological path followed by the author of this essay in his research and, at the same time, inserting escape and consolidation lines of both

\footnotetext{
* Estes escritos foram iniciados em novembro de 2006, em forma de apontamentos para minha fala no seminário organizado pela Associação de Pós-Graduandos da Faculdade de Educação da Universidade Estadual de Campinas (UNICAMP), ocorrido no início de dezembro de 2006, ao qual, ao final, não pude comparecer. Em março de 2007, parti destes primeiros apontamentos para pensar e organizar uma das aulas da disciplina de pósgraduação Geografias de cinema, ministrada por mim. Após esta aula, retomei o texto com a intenção de incluir no mesmo as falas e autores que perpassaram a situação presencial, de modo a dar aos escritos linhas de fuga e adensamentos que aconteceram nas conversas em classe.

** Doutor em Educação e professor da Faculdade de Educação da Unicamp. E-mail: wences@uol.com.br
}

Educ. Soc., Campinas, vol 29, n. 105, p. 1237-1245, set./dez. 2008

Disponível em <http://www.cedes.unicamp.br> 
perspectives. The dialog between Bachelard and the author compose the main text. Thoughts that link and disperse this main dialogue to other authors and ideas are pointed out throughout the whole text.

Key words: Imagination. Research. Poetic image. Gaston Bachelard.

Para Gaston Bachelard, autor do belo livro A poética do espaço, a imaginação é a faculdade de produzir imagens.

É ele quem escreve: "Propomos que se considere a imaginação como um poder maior da natureza humana" (p. 17) e "A imaginação, em suas ações vivas, nos desliga ao mesmo tempo do passado e da realidade. Aponta para o futuro" (p. 17). E é também ele quem completa: "As imagens quase não abrigam idéias tranqüilas, nem idéias definitivas, sobretudo. A imaginação imagina incessantemente e se enriquece de novas imagens" (p. 18)

A seguinte frase de Bachelard resume nossa intenção nestes escritos e nas pesquisas que propomos e desenvolvemos: "É essa riqueza do ser imaginado que queremos explorar" (p. 18).

"O ato poético [tomado como produto da imaginação, portanto como imagem] não tem passado - pelo menos não um passado no decorrer do qual pudéssemos seguir a sua preparação e o seu advento" (p. 5).

É por isso que "é preciso estar presente, presente à imagem no minuto da imagem" (p. 5), uma vez que é no presente da imagem, no nascimento e reverberação dela própria que ela se faz o ser que a produziu ou leu [o pesquisador], que a imagem se faz sujeito e obra dela própria.

"A imagem poética não está submetida a um impulso. Não é o eco de um passado. É antes o
Em outro de seus livros, $O$ ar $e$ os sonhos, Bachelard vai dizer textualmente que a imaginação "é antes a faculdade de deformar as imagens fornecidas pela percepção, e sobretudo a faculdade de libertar-nos das imagens primeiras, de mudar as imagens. Se não há mudança de imagens, união inesperada das imagens, não há imaginação, não há ação imaginante" (p. 1).

Ato poético e imagem poética são aqui tomados não como atos e imagens criativos apenas, mas sim como atos e imagens criadoras. Esta distinção não é uma simples sutileza das palavras, pois o ato e a imagem poéticos se ligam à criação e não somente à criatividade. Se esta última pode ser associada a belos e instigantes rearranjos de coisas já existentes, a criação é sempre inaugural.

Encontro extrema semelhança existente entre a idéia de ato poético em Bachelard e a idéia de nascimento em Hannah Arendt, notadamente no que se refere à relação que estes 
inverso: pela explosão de uma imagem, o passado longínquo ressoa em ecos e não se vê mais em que profundidade esses ecos vão repercutir e cessar. Por sua novidade, por sua atividade, a imagem poética tem um ser próprio, um dinamismo próprio" (p. 5).

Sinto estar aqui muito de nossas buscas com as pesquisas feitas no Laboratório de Estudos Audiovisuais (OLHO) acerca da educação realizada pelas imagens e do processo de educação visual: encontrar persistências de outras imagens nas imagens sobre as quais nos debruçamos em nossas pesquisas; persistências não só pensadas como continuidades ou semelhanças, mas também como origens, no sentido benjaminiano dado a esta palavra. Para nós, portanto, é importante que o pesquisador esteja atento às reverberações daquilo que estuda, às imagens a que ele se dedica, para que os ecos disso em sua vida pessoal lhe tragam outras imagens que se associem às primeiras e lhe tragam outras possibilidades de entendimento e poesia, outras camadas de sentido, outras ressonâncias culturais.

Uma coisa interessante de se notar é a utilização por Bachelard de dois verbos que indicam um retorno - prefixo re - mas que têm "naturezas" um tanto distintas: ressoar e repercutir. Os dois verbos são metáforas auditivas. No entanto, enquanto ressoar é algo diretamente vinculado ao ouvido e ligado aos sons, repercutir tem também em si algo de tátil, ou, mais que isso, de pulsante e vibrátil, indicando um vínculo com o coração e o pulmão peito humano como local da percussão. É por "sair" e "chegar" a ele que "a imagem poética terá uma sonoridade do ser" (p. 6).

"As ressonâncias se dispersam nos diferentes planos da nossa vida no mundo, a reper- dois "eventos humanos" mantêm com o tempo, ou seja, eles não são dedutíveis do passado e nem explicáveis por meio dele, portanto se inserem no mundo como algo que não pode ser previsto, estabelecendo um futuro não dependente nem previsível ou dedutível do passado, mas sim envolvido e contido na novidade que estes eventos trazem ao mundo. É a partir da aproximação entre os escritos destes dois autores que a dimensão política do ato poético - tomado como nascimento - se estabelece com mais nitidez, uma vez que a novidade da imagem - enquanto ato poético - é aquilo que, na esteira do pensamento arendtiano, impede que o mundo se arruíne e, ao mesmo tempo, que o mundo se prepare para os novos que nele ingressam.

A potencialidade/potência da idéia de nascimento em Hannah Arendt aparece no ensaio $O$ enigma da infancia, de Jorge Larrosa, bem como a potencialidade/potência da idéia de arruinamento do mundo aparece nos escritos de Álvaro Tenca acerca da tensão existente entre trabalho e tempo livre na preservação do mundo.

O sentido dado à palavra coração nos vem dos escritos de James Hillman, no livro Cidade e alma. Para este autor, coração seria o local onde a alma se encontra, alma tomada como ânima, como aquilo que nos 
cussão nos chama a um aprofundamento de nossa própria existência. $\mathrm{Na}$ ressonância, ouvimos o poema, na repercussão nós o falamos, pois é nosso (...) parece que o ser do poeta é nosso ser" (p. 9). É aqui que se dá o "nó”, o entrelaçamento entre subjetividade e transubjetividade de que fala Bachelard, algo próximo do sentido de universalidade do humano e da inteireza de nosso corpo. Bachelard vai citar Pontalis para dizer que "o sujeito falante é todo o sujeito" (p. 13). Falamos com o corpo todo, dos pés à cabeça, com alma e espírito vibrando por nós e pelo que está à nossa volta.

"A multiplicidade das ressonâncias sai então da unidade do ser da repercussão" (p. 9). Essa frase é de grande importância para nosso "método", uma vez que aponta o quanto a pluralidade e as potencialidades das dispersóes ressonantes se enraízam (são geradas) no mergulho, na queda gestada pela repercussão de alguma imagem em nosso ser.

Isto se dá porque, na perspectiva de Bachelard, "a imagem se transforma num ser novo de nossa linguagem, exprime-nos, fazendo-nos o que ela exprime, ou seja, ela é ao mesmo tempo um devir de expressão e um devir de nosso ser. No caso, ela é a expressão criada do ser" (p. 10). Aqui é onde encontro a maior conexão com a idéia e importância do desassossego, do choque, do susto, do encontro (com alguma imagem) como "maravilhamento" (o motor do "pensamento", do conhecimento). Ao encontrar essa imagem (e aqui penso que esse encontro se dá num "encontrão", em meio à multidão ou numa esquina, ou ainda num momento de distração. A idéia da distração me chega dos escritos de Clarice Lispector - sempre ela a me dar palavras...), então, ao encontrar tal imagem ela se instala em nós como se fosse nós mesmos. movimenta. Portanto, percutir ou repercutir no coração é fazêlo na alma, esta que é uma palavra normalmente vinculada ao ar, ao sopro, ao vento, remetendo aos pulmóes e à idéia de inspiração, tão cara ao entendimento que temos dos poetas, artistas e criadores. Coração e pulmão, órgãos pulsantes e vibráteis: peito humano como caixa de ressonância para as repercussões que ali se gestam e se enraízam.

Como linha de fuga, nos chegaram os escritos de James Hillman em seu livro $O$ código do ser, no qual o autor expóe a teoria do fruto do carvalho e sua vinculação com as idéias de destino. Esta seria na verdade apenas mais um caminho para se pensar acerca da potencialidadelpotência da vida pessoal - ou do destino pessoal, como diria Hillman - na riqueza de uma pesquisa. Colocando em outras palavras, partindo da imagem do nascimento arendtiano, cada um de nós teria/traz algo de novo para o mundo e é a publicização desta novidade o nosso ato político de maior importância para o mundo - tomado sempre como morada dos homens na terra -, uma vez que é ele - o ato de tornar público a novidade pessoal - que apresenta aos demais uma outra possibilidade de pensar e agir neste mesmo mundo, impedindo que ele se conserve igual 
No entanto, como ela é ainda um vir a ser, não lidamos com ela, não a compreendemos, apenas a "aceitamos" (passivos?!). Enfim, como escreveu a mesma Clarice sobre o "Entendimento", "todas as visitações que tive na vida, elas chegaram, sentaram-se e não disseram nada" (p. 145). Apesar desse "não dizer nada" desta imagem que nos chega num susto, num choque, inserindo em nós um desassossego incompreensível num primeiro momento, entendemos ser ela a imagem de maior potência para o desenvolvimento de uma pesquisa. É ela que seria perseguida pelo pesquisador, tanto em suas repercussóes pessoais quanto em suas ressonâncias no mundo, gerando respectivamente "ensimesmamentos" e "estudos".

Por acreditar nisso é que fazemos coro a Bachelard quando ele nos pergunta: "Por si só, a atitude 'prudente' não será uma recusa em obedecer à dinâmica imediata da imagem?” (p. 6). "Sentimos que a atitude 'objetiva' do crítico sufoca a 'repercussão', recusa, por princípio, a profundidade, de onde deve tomar seu ponto de partida o fenômeno poético primitivo" (p. 10). "A menor reflexão crítica estanca esse impulso [um impulso sincero, um pequeno impulso de admiração] quando coloca o espírito em posição secundária, o que destrói a primitividade da imaginação. Nessa admiração que ultrapassa a passividade das atitudes contemplativas, parece que a alegria de ler é o reflexo da alegria de escrever, como se o leitor fosse o fantasma do escritor" (p. 12). "Não nos parece mais um paradoxo dizer que o sujeito falante [tanto o escritor quanto o leitor] está inteiramente contido na imagem poética, pois, se ele não se entregar a ela sem reservas, não entrará no espaço poético da imagem" (p. 13), uma vez que "trata-se de imagens não-vividas, ao que já é e assim torne-se ruína de si próprio, justamente por não se abrir à chegada dos novos.

É importante destacar o uso deliberado que faço de duas palavras para dizer da repercussão que se dá em nós: $m e r-$ gulho e queda. Enquanto mergulho é uma palavra retirada da própria obra de Bachelard e indica um vetor de atividade, de decisão e ação, queda traz um vetor de passividade, de padecimento e entrega. Entendemos que a repercussão da imagem poética em nós é ao mesmo tempo o nosso mergulho em nós mesmos e nossa entrega a algo que nos ultrapassa e inaugura. Por isso, é que Bachelard vai dizer que a imagem poética ao ser criada ou lida passa a dizer do ser que a criou ou leu.

Como linha de fuga aos escritos de Clarice Lispector, salientou-se a potencialidade/potência da presença de autores e textos da literatura compondo com autores mais acadêmicos no exercício imaginativo, tanto da escrita quanto da pesquisa, se é que há distinção entre elas em muitas de nossas obras como pesquisadores das humanidades, em geral, e da educação, em particular. 
imagens que a vida não prepara e que o poeta cria. Trata-se de viver o invivido e de abrir-se a uma abertura da linguagem" (p. 14). "É preciso então que o saber se acompanhe de um igual esquecimento do saber. O não-saber não é uma ignorância, mas um ato difícil de superação do conhecimento. É a esse preço que uma obra é a cada instante essa espécie de começo puro que faz de sua criação um exercício de liberdade. (...) $\mathrm{Na}$ poesia, o não-saber é uma precondição; se há um ofício no poeta, este se encontra na tarefa subordinada de associar imagens. Mas a vida da imagem está toda em sua fulgurância, no fato de que a imagem é uma superação de todos os dados da sensibilidade" (p. 16).

Aqui está feita toda a reserva que se deve ter às teorias - ou mesmo às experiências -, não porque sejam teorias - uma vez que uma teoria pode nos levar a imaginar - mas porque nossas tradições acadêmicas têm tomado as teorias como fórmulas já prontas para se pensar o mundo e não como pistas, pontes, caminhos para se exercitar a ação imaginante de criar, associar, deformar imagens.

E a toda fulgurância e potencialidade da imagem poética, Bachelard não atribui importância desmesurada, mas muito pelo contrário, diz que "a imagem poética traz uma das experiências mais simples da linguagem vivida" (p. 13). Ela "é o acontecimento psíquico de menor responsabilidade” (p. 12), que "na sua simplicidade nos dá o domínio de nossa língua” (p. 12). Ou seja, é ela que nos revela, nos lembra, nos diz mais claramente que a língua não é somente um conjunto de códigos e sentidos passíveis de serem previstos e utilizados. Ela é também o manancial onde podemos encontrar aquilo
Como linha de fuga, nos chegou a instigante proposta de Bachelard de não incluir as imagens provenientes das lembranças como produtos da imaginação. No entanto, nada impede que as lembranças sejam as imagens primeiras a serem deformadas e associadas a outras tantas pela ação imaginativa. Mas, desta forma, fica a pergunta: de onde viria o ato poético? Viriam as imagens de algum outro tipo de Memória que não a pessoal? Viriam elas de uma Memória que não seria histórica?

Numa relação feita por alguns alunos que cursavam, à época, a disciplina oferecida pelo professor Milton Almeida, veio a proposta de localizar no chamado "mundo imaginal" as imagens de onde nos chegam os atos poéticos. A aproximação com o "mundo imaginal" em sua trans-historicidade trouxe outros autores e idéias para nossas conversas. Foi assim que nos chegaram Jung e Halbwachs, cada um à sua maneira, lidando com maior ou menor proximidade com os historiadores e seus métodos, bem como com as relações entre memória e inconsciente, entre memória e história. Também retornaram os escritos de Hillman sobre o destino inserido na semente do carvalho de nossas almas...

Todas estas foram linhas de fuga que dilataram e tensionaram a busca de algum entendimento para essas imagens poéticas que, apesar de não serem 
que diz de nós mesmos a nós próprios e ao mundo, sem que pudéssemos prever este acontecimento. "A imagem poética é uma emergência da linguagem, está sempre um pouco acima da linguagem significante" (p. 12).

"A imagem, em sua simplicidade, não precisa de um saber. Ela é uma dádiva de uma consciência ingênua. (...) a imagem existe antes do pensamento" (p. 7).

A imagem poética estaria ligada à alma e a uma consciência sonhadora. "Numa imagem poética a alma acusa sua presença” (p. 9).

"A poesia é a alma inaugurando uma forma. A alma inaugura" (p. 9). "A imagem poética existe sob o signo de um ser novo. Esse ser novo é o homem feliz" (p. 14).

Bachelard cita Lapicque, que por sua vez foi citado por Lescure: "Se, por exemplo, pinto a passagem do rio em Auteuil, espero que minha pintura me traga algo de imprevisto, embora de outro gênero, quando me trouxe o curso verdadeiro que vi. Não se pode tratar nem por um instante de refazer com exatidão um espetáculo que já é do passado. Mas necessito revivê-lo inteiramente, agora de uma maneira nova e pictural e, fazendo isso, dar a mim mesmo a possibilidade de um novo choque" (p. 16). Não creio ser coincidência a palavra ser a mesma de Benjamin e Simmel: choque.

Finalizamos estes apontamentos com duas perguntas feitas por Bachelard ao longo de sua introdução ao livro até agora citado, as quais têm profunda relação com as opções de pesquisa que fazemos, notadamente no campo da educação, com toda a sua pretensão em prevenir, cuidar, controlar, prever todas as possibilidades: "Como prever sem imaginar?" (p. 17). “Tornar imprevisível a palavra não será um aprendizado da liberdade?” (p. 12). previsíveis, foram apresentadas como agentes não só do vir a ser pessoal, mas também do futuro do mundo público.

Seria possível pensar os trabalhos acadêmicos como tendo alguma potência poética? Caso eles se desenvolvessem a partir de uma imagem densa poeticamente teriam maior potencial político no jogo do conhecimento e da vida?

É muita pretensão querer que um trabalho acadêmico busque também por sua linguagem, e que ela venha a ser inaugural como a da poesia?

Duas dissertaçôes de mestrado defendidas sob minha orientação fizeram este percurso, de tomar uma imagem e persegui-la em sua potencialidade de mirada para o mundo.

Numa delas, de autoria de Rodrigo Martins Bryan, é a imagem da janela que o leva a mirar a cidade e encontrar seguidas janelas nela: fotografia fotografia noturna da cidade luzes nesta fotografia noturna cores na fotografia noturna de Cássio Vasconcellos.

Na outra, de autoria de Adriano Picarelli, a imagem potente é a dos jardins de mistura, tomados como manifestaçôes de um modo de pensar e viver que tem na mistura um "modo de operar", que adensa nestes jardins estética, ética, colecionismo, biografias na relação entre pessoas e natureza nas cidades. 
Nossa resposta para esta última pergunta seria sim, na medida em que assumimos a imprevisibilidade das palavras como um aprendizado da liberdade de imaginar. Nossa dúvida quanto ao exercício desta liberdade é dirigida ao quanto dela suportamos ou suportaríamos na universidade, nas pesquisas que realizamos.

Ao tomar a primeira das perguntas nas mãos, fica o desafio do imaginar como exercício do pesquisar, entendendo pesquisar como um dos exercícios, e dos riscos, do prever...

Recebido em maio de 2008 e aprovado em setembro de 2008.
A linha de fuga à palavra choque se faz na direção das obras dos dois autores citados, Walter Benjamin e Georg Simmel, e de seus escritos sobre a experiência da vida na cidade como marco da modernidade e das novas formas de estar no mundo que ela inaugura: a experiência como choque, tantas vezes restrito à sua única ocorrência; o excesso de choques proveniente da vida urbana, levando ao fim da experiência e a uma atitude que se aproxima da indiferença no relacionar-se das pessoas com as outras e com o mundo à sua volta.

\section{Referências}

ALMEIDA, M. J. Cinema: arte da memória. São Paulo: Autores Associados, 1999.

ARENDT, H. A condição humana. Rio de Janeiro: Forense; EDUSP, 1981.

ARENDT, H. Crise na cultura. In: ARENDT, H Entre o passado e o futuro. São Paulo: Perspectiva, 1979.

ARENDT, H. Crise na educação. In: ARENDT, H Entre o passado e o futuro. São Paulo: Perspectiva, 1979.

BACHELARD, G. A poética do espaço. Rio de Janeiro: Eldorado, 1972.

BACHELARD, G. O ar e os sonhos. São Paulo: Martins Fontes: 1990.

BENJAMIN, W. O narrador. In: Benjamin, W. Obras escolhidas. v. 1. São Paulo: Brasiliense, 1985.

BENJAMIN, W. Sobre alguns temas em Baudelaire. In: Os Pensadores Walter Benjamin. São Paulo: Abril Cultural, 1980.

BRYAN, R.M. A cidade e suas janelas: espaço e tempo na noite urbana. 2006. 86f. Dissertação (mestrado) - Faculdade de Educação da Universidade Estadual de Campinas, Campinas. 
GAGNEBIN, J. História e narração em Walter Benjamin. Campinas: Editora da UNICAMP, 1994.

HALBWACHS, M. A memória coletiva. São Paulo: Vértice, 1990.

HILlMAN, J. Cidade e alma. São Paulo: Studio Nobel, 1993.

HILLMAN, J. O código do ser. Rio de Janeiro: Objetiva, 1997.

JUNG, C.G. O Eu e o inconsciente. Petrópolis: Vozes, 1987.

LARROSA, J. O enigma da infância. In: Larrosa, L. Pedagogia profanadanças, piruetas e mascaradas. Belo Horizonte: Autêntica, 1999.

LARROSA, J. Notas sobre a experiência e o saber da experiência. Revista Brasileira de Educação, Rio de Janeiro, n. 19, p. 20-28, abr. 2002. Disponível em: <http://www.anped.org.br/rbe19/03-bondia.pdf> Acesso em: 12 abr. 2007.

LISPECTOR, C. Para não esquecer. São Paulo: Siciliano, 1992.

OLIVEIRA JR., W.M. O que seriam as geografias de cinema? Revista txt - leituras transdisciplinares de telas e textos, Belo Horizonte, n. 2, p. 1-9, dez. 2005. Disponível em: <http://www.letras.ufmg.br/atelaeotexto/ revistatxt2/wenceslao.htm>. Acesso em: 12 abr. 2007.

PICARELLI, A. Jardins de mistura: imagens e memórias. 2007. $161 \mathrm{f}$. Dissertação (mestrado) - Faculdade de Educação da Universidade Estadual de Campinas, Campinas.

SIMMEL, G. A metrópole e a vida mental. In: Velho, O. (Org.). O fenômeno urbano. Rio de Janeiro: Zahar, 1967.

TENCA, A. Necessidade e liberdade: trabalho e tempo livre na produção e preservação do mundo dos homens e das coisas. In: TencA. A. Senhores dos trilhos. São Paulo: Editora da UNESP, 2006. 